\title{
Qatar 2022 World Cup and its legacies: How to promote sustainable and livable open spaces in the city of Doha through mega sports events?
}

Simona Azzali*

Architecture and Urban Planning, Qatar University, Doha, Qatar

^Email: simoazza@tiscali.it; sa1305277@qu.edu.qa http://dx.doi.org/

10.5339/qproc.2016.qgbc.4

(c) 2016 Azzali, licensee HBKU Press. This is an open access article distributed under the terms of the Creative Commons Attribution license CC BY 4.0, which permits unrestricted use, distribution and reproduction in any medium, provided the original work is properly cited.

\section{ABSTRACT}

With the aim of diversifying its economy and develop itself as a tourist destination, in recent years, Qatar has hosted many international sports events and will host the 2022 FIFA World Cup. Doha, Qatar's capital city, is literally under construction, and is facing important changes in terms of transportation, infrastructure, and sports facilities. However, past experiences have shown that the outcomes of staging major sports events are mostly harmful, and their planned legacies last only for a short time. This trend becomes even stronger when considering how sports facilities and their surroundings are utilized after the event is over. Usually, sports venues become white elephants, and their neighborhoods islands of placelessness, underutilized and abandoned pieces of the city. What will be left after the World Cup? How to leverage this event as a moment of experimentation and sustainable growth of its capital city, Doha? In this context, the aim of this research is to identify strategies to plan and maximize the post-event usage of event sites and venues, and make their neighborhoods more livable and sustainable. The research has a specific focus on the city of Doha, which hosted the 2006 Asian Games and will host the 2022 FIFA World Cup. It starts with a critical review of relevant precedents from the Western and the Eastern world, and then continues with an indepth analysis of three selected case studies, namely the cities of London, Sochi, and Rio de Janeiro that recently hosted major sports events. Finally, the research focuses on the context of Doha, investigating its public spaces and planning system, and analyzing the government's legacy plans for the 2022 World Cup. The expected results include a set of guidelines and recommendations to help Doha transform its sports venues and event sites into lasting, sustainable, and livable public open spaces, and, more generally, to define strategies for achieving successful legacies from the host of mega sports events. The results of this research can also be applied to other Gulf cities that share many similarities in terms of their urban form and planning systems, and that face for the first time the challenges and opportunities offered by the host of mega events.

Keywords: Qatar 2022, sustainable legacies, livable open spaces, Doha; mega sports events 